\title{
Complications of high volume circumcision: glans amputation in adolescents; a case report
}

\author{
Mmatsie Manentsa, Hilary Mukudu, Nthabiseng Koloane, Ashley Ringane, Eleanor Matta, Neil A. Martinson and \\ Limakatso Lebina* (1)
}

\begin{abstract}
Background: The past four years has seen a rapid roll-out of male medical circumcision services in South Africa in response to clinical trials showing circumcision prevents HIV acquisition in heterosexual men. Clinics conduct substantial numbers of circumcisions per day. We report three cases of glans amputation in adolescents attending high volume clinics where modified Models of Optimising Volume and Efficiency (MOVE) are implemented.
\end{abstract}

Case presentations: Three cases of glans amputation in young healthy men that presented for voluntary medical male circumcision. The procedures were performed by highly experienced medical officers in two cases. All these cases shared characteristics: younger males with immature genitalia, forceps guided circumcision, and likely operator fatigue. Voluntary male medical circumcision programs should include regular monitoring and evaluation and training of operators to ensure high quality surgical techniques such as working in clean areas and taking frequent breaks.

Conclusion: Circumcision is a relatively simple medical procedure, however regular training and quality control in high volume Male Medical Circumcision sites is essential to prevent rare catastrophic adverse events.

Keywords: MMC, Adverse events, HIV prevention, Surgical circumcision

\section{Background}

In 2007 the World Health Organisation (WHO) recommended that countries with low levels of circumcision, high HIV prevalence rates and mainly heterosexual Human Immunodeficiency Virus (HIV) transmission levels should scale-up access to safe male circumcision services [1]. The WHO in its Joint Strategic Action Framework 2012-2016, outlined steps necessary to implement scale-up [2]. The framework made a call for innovative strategies to be employed in the scale-up. These strategies included innovative use of human resources through Models for Optimizing the Volume and Efficiency (MOVE) of male circumcision services [2, 3]. The MOVE model for VMMC services enhances efficiency by coordinating client flow, using multiple

\footnotetext{
*Correspondence: lebinal@phru.co.za

Perinatal HIV Research Unit (PHRU), SA MRC Soweto Matlosana Collaborating Centre for HIV/AIDS and TB, University of the Witwatersrand, Johannesburg, South Africa
}

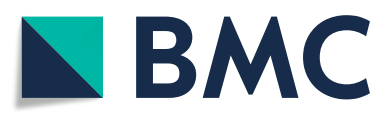

() The Author(s). 2019 Open Access This article is distributed under the terms of the Creative Commons Attribution 4.0 International License (http://creativecommons.org/licenses/by/4.0/), which permits unrestricted use, distribution, and reproduction in any medium, provided you give appropriate credit to the original author(s) and the source, provide a link to the Creative Commons license, and indicate if changes were made. The Creative Commons Public Domain Dedication waiver (http://creativecommons.org/publicdomain/zero/1.0/) applies to the data made available in this article, unless otherwise stated.

surgical beds to one surgical team, task shifting of some (suturing) surgical procedures to non-physicians and use of pre-packed consumables [3].

In 2010 the South African National Department of Health (DoH) began large scale roll-out of Voluntary Medical Male Circumcision (VMMC) [4]. To date approximately 2,84 million circumcisions have been conducted at multiple high-volume VMMC clinics across the country [5]. Since the roll-out began, moderate adverse events have been reported occurring in fewer than $2 \%$ of patients circumcised $[5,6]$. It is important for the management of male circumcision programs both in South Africa and elsewhere that adverse events be reported as there are rare instances of severe complications, which should be monitored and responded to, thereby preventing future events [7].

Our organisation managed implementation of VMMC in five high volume clinics. Informed consent was obtained from presenting males, and for those under 18, 
parental consent was obtained as well. Pre-operation screening and surgical preparation was done as per the WHO's Manual for Male Circumcision under Local Anaesthetic [6].

As part of quality control, we reviewed three glans amputations that occurred at these high volume VMMC clinics and report them as a case series. To obtain the data, a retrospective record review was conducted at the three clinics, together with one-on-one interviews conducted with medical officers and other staff members involved in the cases.

\section{Case presentations Case 1}

The first case occurred in 2016 at a VMMC clinic established in 2010 in an urban township. The clinic staff numbered 26 including, medical officers, clinical associates, nurses, and support staff. On the day of the event, at total of 97 circumcisions were performed at the clinic, 22 of these by the operator involved in the glans amputation prior to the incident. The case was a 10-year-old boy who presented for medical male circumcision. The operator was a medical officer, with experience of over 13,000 circumcisions, assisted by an enrolled nurse. A total of $7 \mathrm{ml}$ local anaesthetic was injected using the penile ring block technique $(4,5 \mathrm{ml}$ lignocaine $2 \%$ plus $2,5 \mathrm{ml}$ marcaine $0,5 \%$ ) [5]. As the patient's penis was relatively small, the volume of local anaesthetic applied caused ballooning of the penis from the base to the tip of the foreskin. The forceps guided circumcision technique was used according to then standard protocols [6]. The operative procedure was initiated at $16 \mathrm{~h} 10$. After the operator clamped the foreskin with the forceps, the glans was palpated to ensure that it was below the clamp. When the foreskin was excised, it became clear that the glans had been amputated at a level just below the coronal sulcus.

Haemostatic control of the wound was maintained through compression and the amputated glans was placed on ice. The urologist on call was contacted to immediately assess the patient, and within $40 \mathrm{~min}$ the patient was taken into theatre for urgent repair and reconstruction. The glans was successfully re-attached during surgery, a catheter was inserted until the wound was healed. Based on patient feedback, he subsequently, developed a fistula and had to undergo further reconstructive surgery.

\section{Case 2}

The second case occurred in 2013 involving a 15 -year-old boy who presented for medical male circumcision at a VMMC clinic established in 2012. The clinic staff numbered 22 including managers, medical officers, nurses, and support staff. On the day of the incident 58 circumcisions had been performed, 34 of these by the operator prior to the incident. As in the previous case, after informed consent was sought from the boy's guardian, standard guidelines were followed in the screening and surgical preparation. The operator was a medical officer, who had completed 8000 circumcisions, assisted by 2 nurses. The surgical technique used in the procedure was the forceps-guided method. Local anaesthetic, $2 \mathrm{ml}$ Marcaine $0,5 \%$ plus $8 \mathrm{ml}$ lignocaine $2 \%$, was injected into the base of the penis via ring block using a syringe and needle with marked swelling of the penis from the base of the penis to the foreskin. The operative procedure was initiated at $15 \mathrm{~h} 19$. The operator clamped the foreskin with a forceps and palpated for the position of the glans. As the foreskin was excised the operator noticed that the glans had been partially amputated and the urethra was exposed. The procedure was abandoned and haemostatic control was maintained whilst a urologist was called in to assess the patient. A partial distal glans amputation was diagnosed by the attending urologist and within $3 \mathrm{hrs}$ the patient was taken to theatre for repair and reconstruction. Glans reconstruction was attempted with re-attachment of the transacted part of the glans and catheter inserted. However, post-operatively, a large portion of the reattached glans became necrotic and the patient subsequently developed a urethro-cutaneous fistula. The patient required further reconstruction.

\section{Case 3}

The third case was a 10-year-old boy occurred at a VMMC clinic situated in a rural area. The clinic was established in 2012 and has a total staff complement of 22, including medical officers, clinical associates, nurses and other support staff. On the day of the incident, 120 circumcisions were performed at the clinic. The operator involved was a clinical associate (a cadre of staff with four years of medical training and licensed to do circumcisions) with experience of over 1000 circumcisions. He performed 25 circumcisions that day prior to the incident. The patient was consented and screened as in the previous two cases. The procedure started at $12 \mathrm{~h} 30$, using a modified forceps guided circumcision as the patient had phimosis. Local anaesthetic was injected by penile ring block using $3 \mathrm{ml}$ lignocaine $2 \%$ and $1 \mathrm{ml}$ Marcaine $0,5 \%$. After the dorsal slit was made, preputial adhesions were released and the glans was palpated before the forceps was clamped. After the foreskin was excised the operator noted a partial amputation of the glans on the dorsal aspect, the urethra was not involved. A medical officer was immediately called to assist. A urethral catheter was inserted and haemostatic control of the wound was achieved through cauterisation and sutures. The patient was referred to a hospital for further reconstruction by a urologist. The patient has healed without sequelae. 
The total number of men and boys under 15 years, and those 15 years and over circumcised in five high volume male circumcision clinics under the same administration as the three clinics where the glans amputation occurred was 17,551 and 53,782, respectively, yielding rates of glans amputation of 11.3/100000 and 1.8/100000 in those younger than 15 years, and 15 years of age or older, respectively $(p=0.0126)$.

\section{Discussion}

Voluntary medical male circumcision is a common and safe medical procedure with frequencies of complications ranging between 1 and 15\% [7]. Most adverse events are mild, but severe complications occur occasionally, and include necrosis of the glans, penile amputation, urethral fistulas and preputial fusion $[7,8]$. Complications appear to be higher in older children when compared to neonatal circumcision [9]. In two cases we report, anatomy of the penis was underdeveloped. Both cases reported excessive swelling of the penis after injection of local anaesthetic making it difficult for operators to adequately palpate the glans. In such cases the forceps-guided method is not the best choice. A dissection or resection method would be a safer option.

A higher rate of adverse events have been reported with circumcisions performed by providers with less experience [9]. The operators in the first two cases were both medical officers with extensive surgical experience in MMC. However, the operator in the third case was a clinical associate who had considerably less experience. Both the VMMC clinics where these amputations occurred utilised task-shifting and task-sharing, as recommended by the MOVE principles $[3,10]$. Studies have reported no difference in adverse event rates when these strategies are implemented [11]. However, the operator does not examine the patient during eligibility screening, and may only see the patient at the time of the procedure. This does not give the operator sufficient time to consider and plan alternative surgical options when presented with potentially difficult circumcisions. In the first two cases the glans amputation occurred after each operator had already completed over 20 circumcisions. All three events occurred in the afternoon when the operators were most likely fatigued.

Our experience suggests that in high volume circumcision clinics, strict rules be applied to prevent catastrophic adverse events like amputation or partial amputation of the glans. We propose that firstly, no young children (younger than 13 years) should be circumcised in the afternoon, by clinical staff that performed MMC procedures that morning. Secondly, frequent breaks (at least every 1-2 hrs) be given to operators when they doff all protective equipment, and leave the operating theatre for at least $15 \mathrm{~min}$. Consideration should be given to setting a maximum daily cap on the number of men circumcised by an individual surgeon. Thirdly, in young adolescents additional care must be taken: the attending surgeon must individually examine the child before a decision to circumcise is made, thereby noting the maturity of the genitals before starting the procedure; local anaesthetic injected subcutaneously should dissipate, allowing restoration of anatomical landmarks before first incision and dissection. Fourthly, MMC guidelines should recommend the use of open surgical techniques (dorsal slit) that ensure visualisation of the glans prior to excising the foreskin and managers of VMMC programs must ensure that this is adhered to. Fifthly, there should be continuous training and retraining of all ranks of MMC providers, with on-going monitoring and evaluation to ensure quality control. Finally, implementation of a neonatal circumcision program would likely prevent such events, as a systematic literature review has shown there are minimal severe adverse events (infection, ulcers) and no glans amputations with neonatal circumcision [9].

Higher rates of adverse events have been reported during mass circumcision campaigns, mainly related to non-sterile conditions and a lack of equipment [12]. The rapid scale-up of VMMC services in South Africa has reportedly led to a decline in quality of services [10]. This decline is related to the distribution of limited resources as the programme expands and is said not to reflect the quality of surgical technique [13]. A worrying aspect of increased adverse events is the rise in medical liability litigation which may act as a barrier to the provision of VMMC [14]. Severe complications during medical male circumcision occur occasionally, and providers of VMMC services must conduct regular introspection, and quality reviews to ensure service quality is improved and adverse events that we have described, are avoided.

\section{Abbreviations}

CDC: Centre for Disease Control; DOH: Department of Health; HIV: Human Immunodeficiency Virus; MMC: Male Medical Circumcision; MOVE: Models of Optimising Volume and Efficiency; VMMC: Voluntary Male Medical Circumcision; WHO: World Health Organisation

\section{Acknowledgements \\ The authors would like to thank the clinics cases were conducted, the nurses that assisted and the individuals that were studied.}

Ethics approval consent to participants Not applicable.

Funding

Not applicable.

Availability of data and materials

Data sharing is not applicable to this article as no datasets were generated or analysed during the current study. 


\section{Authors' contributions}

MM, HM, EA, NAM, and LL conceptualised the idea of the case report manuscript and collated data on the case reports. MM, NK, AR NAM and LL were involved in the drafting and critical review of the manuscript. All authors read and approved the final manuscript.

\section{Consent for publication}

Written consent for publication was obtained from the patients and a legal guardian for minors.

\section{Competing interests}

The authors declare that they have no competing interests.

\section{Publisher's Note}

Springer Nature remains neutral with regard to jurisdictional claims in published maps and institutional affiliations.

Received: 13 August 2018 Accepted: 17 April 2019

Published online: 11 July 2019

\section{References}

1. World Health Organization. UNAIDS. New data on male circumcision and HIV prevention: policy and programme implications, vol. 2013. Geneva, Switzerland: World Health Organization; 2007.

2. World Health Organization. UNAIDS joint strategic action framework to accelerate the scale-up of voluntary medical male circumcision for HIV prevention in eastern and southern Africa, 2012-2016. Geneva; 2011.

3. World Health Organization. Considerations for implementing models for optimizing the volume and efficiency of male circumcision services. 2010.

4. Rees H. PIC and SANAC end of term review of the NSP 2007-2011 final report 4; 2011

5. World Health Organization. Progress brief - voluntary medical male circumcision for HIV prevention in 14 priority countries of east and southern Africa, vol. 2017. Geneva; 2017.

6. World Health Organization. Manual for male circumcision under local anaesthesia. Geneva; 2011.

7. Ceylan K, Burhan K, Yllmaz Y, Can S, Kus A, Mustafa G. Severe complications of circumcision: an analysis of 48 cases. J Pediatr Urol. 2007;3(1):32-5.

8. Johnson PRV. Childhood circumcision. Surgery (Oxford). 2005;23(9):338-40.

9. Weiss HA, Larke N, Halperin D, Schenker I. Complications of circumcision in male neonates, infants and children: a systematic review. BMC Urol. 2010;10(1):2

10. Rech D, Spyrelis A, Frade S, Perry L, Farrell M, Fertziger R, et al. Implications of the fast-evolving scale-up of adult voluntary medical male circumcision for quality of services in South Africa. PLoS One. 2014;9(5):e80577.

11. Ford N, Chu K, Mills EJ. Safety of task-shifting for male medical circumcision: a systematic review and meta-analysis. AIDS. 2012;26(5):559-66. https://doi. org/10.1097/QAD.0b013e32834f3264.

12. Özdemir E. Significantly increased complication risks with mass circumcisions. Br J Urol. 1997:80(1):136-9.

13. Sgaier SK, Reed JB, Thomas A, Njeuhmeli E. Achieving the HIV prevention impact of voluntary medical male circumcision: lessons and challenges for managing programs. PLoS Med. 2014;11(5):e1001641.

14. Evens E, Lanham M, Hart C, Loolpapit M, Oguma I, Obiero W. Identifying and addressing barriers to uptake of voluntary medical male circumcision in Nyanza, Kenya among men 18-35: a qualitative study. PLoS One. 2014;9(6):e98221.

Ready to submit your research? Choose BMC and benefit from:

- fast, convenient online submission

- thorough peer review by experienced researchers in your field

- rapid publication on acceptance

- support for research data, including large and complex data types

- gold Open Access which fosters wider collaboration and increased citations

- maximum visibility for your research: over $100 \mathrm{M}$ website views per year

At $\mathrm{BMC}$, research is always in progress.

Learn more biomedcentral.com/submissions 